\title{
Os equilíbrios da unidade camponesa: contribuição teórico-metodológica para o estudo do mundo rural em geografia
}

\begin{abstract}
The peasantry organism equilibriums: a theoretical and methodological contribution to the rural scenario study in geography field.
\end{abstract}

Heitor Nascimento Mendes'; Marcelo Cervo Chelotti"

\begin{abstract}
RESUMO
Considerando as diferentes abordagens e concepções acerca do campesinato nas ciências sociais, em especial na Geografia, as quais trazem metodologias diversas e buscam uma compreensão aprofundada das transformações socioespaciais a que tais grupos estão sujeitos, objetiva-se no presente texto contribuir teórico-conceitualmente com uma estratégia metodológica para os estudos rurais em Geografia, pautada nos equilíbrios camponeses identificados por Alexander Chayanov, e posteriormente trabalhados e reelaborados por Jan Douwe van der Ploeg à luz dos novos tempos. Para tanto, propomos discutir a importância da releitura de Chayanov no contexto atual, bem como a confiabilidade das variáveis presentes nos equilíbrios, articulando-os com a subjetividade e a reciprocidade inerente às sociedades camponesas. Desse modo, buscamos oferecer um arcabouço teórico importante para a compreensão das transformações e da reprodução sociocultural do campesinato diante da sua relação com a agricultura capitalista, sua organização e as diferentes conjunturas diante de sua territorialização.
\end{abstract}

Palavras-chave: Abordagem Chayanoviana; Equilíbrios camponeses; Geografia Rural; Mundo Rural; Unidade Camponesa

\begin{abstract}
Considering distinct approaches and concepts about peasantry perspective in social sciences, especially in Geography, that brings different methodologies and seek an in-depth comprehension of sociospatial transformations where these groups are inserted, this article aims to contribute theoretically and conceptually, as a methodological strategy to rural studies in this field, based on the peasant equilibrium roposed by Alexander Chayanov, and later worked and reworked by Jan Douwe van der Ploeg projecting the new times. Therefore, we intend discuss the relevance of Chayanov's rereading in the current context, such as the reliability of variables inserted in the respective equilibrium, articulating them with the subjectivity and reciprocity imbricated in peasant societies. In this sense, we seek to offer a considerable relevant theoretical comprehension outline based on peasantry transformations and socio-cultural reproductions due to its relationship allied to capitalist agriculture, to its organization and different circumstances that runs for of its territorialization.
\end{abstract}

Keywords: Chayanovian Approach; Peasantry equilibrium; Rural Geography; Rural Scenario; Peasantry Organism

' Universidade Federal de Uberlândia-MG- Brasil - https://orcid.org/0000-0001-9242-8853 - heitor1001@hotmail.com

" Universidade Federal de Uberlândia-MG- Brasil - http://orcid.org/0000-0002-5236-7272 - chelotti@ufu.edu.br 


\section{INTRODUÇÃO}

Nas últimas décadas é notória a dedicação de pesquisadores em Geografia aos estudos sobre campesinato. Eventos e discussões realizadas no Brasil e na América Latina, a exemplo do Encontro Nacional de Geografia Agrária (ENGA), do Simpósio Internacional de Geografia Agrária (SINGA) e do Encontro de Geógrafos da América Latina (EGAL), bem como as diversas publicações em periódicos específicos e os debates acadêmicos, demonstram os esforços para a compreensão das transformações e as distintas abordagens relativas a esses grupos e aos impactos a que estão sujeitos.

Nesse sentido, figuram como elementos cruciais das análises, as metodologias empregadas e a possibilidade de revisão e movimentação das teorias clássicas e contemporâneas à luz de seu tempo, de acordo com as questões observadas em determinado período e local. Tais práxis teoria-empiria são imprescindíveis e devem ser trabalhadas de forma mais aprofundada.

A proposta metodológica ora apresentada, com base nos equilíbrios camponeses identificados e trabalhados por Jan Douwe van der Ploeg (em uma perspectiva chayanoviana), contribui teoricamente com os estudos sobre 0 campesinato no âmbito dos estudos rurais em Geografia. Embora o autor não seja geógrafo, suas perspectivas dialogam com uma abordagem interdisciplinar necessária a tais investigações.

Com o escopo de alavancar os elementos trabalhados por Ploeg (2016) e Chayanov (1974), será apresentada uma proposta metodológica estruturada basicamente nos equilíbrios, porém ampla e aberta a possibilidades, posto que eles não são restritos e estão sujeitos a renovações ou mesmo a identificações outras, diante de determinada realidade histórico-geograficamente estabelecida.

O presente texto está organizado em três partes, além da introdução e das considerações finais. Na primeira parte é ressaltada a importância da releitura de Chayanov para a presente discussão; posteriormente são discutidos os equilíbrios 
relacionais e a confiabilidade de suas variáveis; e na terceira salienta-se a subjetividade e o papel da reciprocidade nas sociedades camponesas.

\section{RELEITURAS NA ABORDAGEM CHAYANOVIANA}

Historicamente, a produção do território camponês está se dando de forma paralela ao desenvolvimento do capitalismo no campo, e suas expressões e transformações advêm da relação conflituosa estabelecida entre ambos. O uso da terra para fins de acumulação resulta em novas territorialidades e formas de manter e reorganizar seus equilíbrios internos.

Para tanto, os territórios alternativos ao avanço do capital sustentam fortes discussões acerca de sua capacidade de manutenção e das transformações a que estão sujeitos, a exemplo do que ocorreu de forma expressiva no início do século XX na Rússia, quando pensadores de diferentes vertentes buscaram compreender as metamorfoses empreendidas no campo conforme o desenvolvimento do capitalismo naquele país.

Tais concepções se vinculavam, como assinalado por Ploeg (2016), em questões fortemente inter-relacionadas, sendo que:

(...) as mais importantes se debruçavam, antes de mais nada, na definição da posição de classe do campesinato - uma questão que estava nitidamente ligada a assuntos práticos, como a natureza das coalizões e o papel que partes distintas da população pode exercer em processos revolucionários. Em segundo lugar, havia extenso debate sobre a estabilidade das formas (ou "modos") de produção do estilo camponês. Será que eles inevitavelmente se desintegrariam ou seria possível serem reproduzidos ao longo do tempo? Ou haveria processos desiguais, porém combinados, de desaparecimento e reconstituição? Em terceiro lugar, as pessoas envolvidas na transição para o socialismo consideram a agricultura camponesa como algo a ser continuado ou transformado? (PLOEG, 2016, p. 4).

Representada por autores como Kautsky (1986) e Lenin (1980), parte dos marxistas ortodoxos não acreditavam, naquele momento, na permanência do campesinato frente ao avanço do capital no campo. Isso poderia estar ligado especificamente ao processo em curso na Rússia ou seria observável em diversas 
partes do mundo, em que tal nação seria apenas mais uma representante, guardando suas particularidades.

O processo de desintegração do campesinato, de acordo com a corrente ortodoxa, se daria a partir da proletarização ou expropriação dos camponeses, ou mesmo de uma diferenciação interna ao grupo, a qual levaria à constituição de camponeses pobres, que se tornariam trabalhadores assalariados; e ricos, que passariam a ser pequenos capitalistas. Essa diferenciação ocorreria em virtude da modernização do campo, não havendo lugar para a pequena produção e a manutenção dos modos de vida camponeses na sociedade emergente.

Porém, o campesinato não se findou com o avanço do capital. Ao contrário do que se propunha, tais grupos continuaram se reinventando e se reestruturando diante dessa relação. Formas ditas não capitalistas de produção passaram a integrar as ruralidades contemporâneas a esse debate, quando aquele se mostrou incapaz de oferecer possibilidades de trabalho e renda à maioria da população rural.

Em contraposição às teorias e crenças de Kautsky e Lenin, Chayanov (1974) assinalava, a partir de estudos sobre o núcleo familiar camponês, que o campesinato apresentava relações e equilíbrios internos distintos daqueles averiguados pela forma capitalista. De acordo com ele, haveria grande heterogeneidade em cada unidade camponesa, as quais se mostravam capazes de se adaptar e se reconstituir segundo relações distintas aos modelos "externos".

O ponto central da perspectiva chayanoviana é observar que, embora a unidade de produção camponesa esteja condicionada e seja afetada pelo contexto capitalista em que funciona, não é diretamente governada por ele. $\mathrm{Na}$ verdade, é governada por um conjunto de equilíbrios. Tais equilíbrios associam a unidade camponesa, seu funcionamento e seu desenvolvimento, ao contexto capitalista mais amplo, porém de formas complexas e definitivamente distintas. Esses equilíbrios são princípios de organização. Eles modelam e remodelam o modo como os campos são lavrados, como o gado é criado, como o trabalho de irrigação é construído e como as identidades e relações mútuas se desenrolam e se concretizam (PLOEG, 2016, p. 9)

No âmbito dessa complexidade de equilíbrios, a heterogeneidade da agricultura camponesa se estabelece. Chayanov pôde identificá-los e construir uma teoria oposta aos marxistas clássicos, o que levou a severos debates e influenciou 
uma gama de pensadores e teóricos que o procederam. Para ele, não haveria uma dissolução do campesinato, e sim, a partir dos equilíbrios internos, a sua constante reinvenção conforme as condições dadas pelo capitalismo.

A diferenciação, para Chayanov, longe de ser possibilidade de descamponização, era uma estratégia de manutenção da condição de camponês diretamente relacionada com o ciclo de desenvolvimento da família e, portanto, indispensável à compreensão da permanência camponesa. Para o autor, o que estava em curso no campo russo não era um processo de desigualdade e antagonismo de classe no seio do campesinato, numa competição própria da lógica capitalista que levaria inflexivelmente à desintegração do mundo camponês. Mas, sim, um conjunto de estratégias orientadas por uma racionalidade que partia da família para a terra, portanto, da avaliação subjetiva das necessidades do núcleo familiar. (PAULINO; ALMEIDA, 2010, p. 33).

Apesar da heterogeneidade, os equilíbrios da unidade camponesa, para Chayanov, se baseavam em quatro elementos fundamentais - trabalho, consumo, utilidade e penosidade -, os quais deveriam ser balanceados em cada uma dessas unidades (PLOEG, 2016). Tais equilíbrios se restringiam à capacidade organizativa da família no âmbito da propriedade e, apesar de abarcarem aspectos externos (mercado, obtenção de recursos, dependência etc.), eles os incorporavam apenas a esses elementos. Para fins de análise, eles serão denominados como "equilíbrios estritos", por se associarem diretamente a unidade camponesa.

Nesses termos, a relação entre trabalho e consumo, bem como entre utilidade e penosidade, perpassa as unidades e instituem a unicidade de cada núcleo familiar camponês. Como dito por Paulino e Almeida (2010), conta-se mais o caráter subjetivo da família, suas capacidades, aptidões, escolhas, enfim, as possibilidades diante da força de trabalho, do lazer, do consumo, entre outras.

O equilíbrio entre trabalho e consumo se refere à capacidade produtiva da família, à quantidade e à qualidade do trabalho empregado, além das variadas nuances das atividades exercidas na propriedade. Esta, por sua vez, pode abarcar 
diferentes gerações, períodos (com maior ou menor capacidade de aferir trabalho) ou mesmo necessidades compreensíveis apenas no nível micro na unidade camponesa, tais como lazer, quantidade necessária para abarcar o consumo total da família, aptidões para o trabalho etc.

Já o equilíbrio entre utilidade e penosidade se vincula aos esforços para aumentar a renda e os recursos da família, os quais são úteis para serem reproduzidos e para a manutenção da propriedade. Dificuldades encontradas no trabalho como a labuta diária com o gado e as plantações, as horas no sol, na chuva ou qualquer outra intempérie que dificulte esse processo, bem como questões temporárias que mudem a rotina de trabalho, enfim, tudo que é potencialmente penoso deve ser levado em consideração. A família camponesa se equilibra com o que Ihe é útil ou necessário, objetiva e subjetivamente.

Diante desse fato, ao satisfazer as necessidades de consumo da família em dado período, o camponês poderá diminuir sua carga de trabalho, diminuindo assim sua penosidade, a partir do momento em que, aquilo que lhe é útil, tenha sido contemplado. O contrário também pode ser observado: se por alguma adversidade, as necessidades da família não foram sanadas, os esforços deverão ser aumentados para que se atinja tal objetivo.

A partir dessa perspectiva, Ploeg (2016) propõe uma ampliação da teoria de Chayanov, buscando identificar equilíbrios para além daqueles descritos anteriormente (trabalho-consumo e penosidade-utilidade). Ele considera que tais aspectos podem oferecer bases para a identificação das formas organizativas atuais do campesinato, modernizando o conceito e a própria teoria de Chayanov, restrita ao tempo e ao espaço de sua época.

Por um lado, a gama mais ampla de equilíbrios (...) se relaciona aos dois equilíbrios discutidos exaustivamente por Chayanov (...). Por outro lado, esse conjunto mais amplo de equilíbrios - desenvolvidos dentro da tradição conhecida como abordagem chayanoviana - nos permite lidar melhor, de forma coerente, com os problemas e potenciais enfrentados pela unidade camponesa hoje. O mesmo conjunto de equilíbrios também ajuda a explicar a 
considerável heterogeneidade que existe entre o campesinato, entre e dentro de países e regiões (PLOEG, 2016, p. 59).

Ademais, Ploeg (2016) destaca outros cinco equilíbrios, abrindo espaço para uma abordagem mais ampla e que não se finda com os equilíbrios já identificados. É, portanto, uma renovação dos trabalhos de Chayanov, vista como um caminho inevitável para a compreensão do campesinato no século XXI.

\section{OS EQUILÍBRIOS RELACIONAIS: UMA OBTENÇÃO CONFIÁVEL DE VARIÁVEIS}

Como destacado, os equilíbrios trabalhados por Ploeg (2016), dão suporte a uma análise mais ampla que abarca diferentes esferas da vida dos camponeses e de suas relações com a produção, os recursos e a natureza. Por esse motivo eles podem ser uma opção metodológica para a análise das especificidades das disputas territoriais e da constituição dos territórios camponeses.

É essencial destacar também a importância da categoria tempo para a presente proposta. É inevitável que tais equilíbrios variem de forma pouco previsível durante intervalos de tempo específicos, sendo necessário assim um bom recorte temporal, estabelecendo objetivos possíveis de serem alcançados dentro desses limites. Análises anteriores a esse período ou projeções devem prever maior cuidado em relação à obtenção de dados e às informações utilizadas.

O quadro 1 apresenta uma síntese dos equilíbrios propostos por Chayanov (1974) e Ploeg (2016), assim como os parâmetros de análise discutidos no presente trabalho. Há equilíbrios relativos ao núcleo familiar e seu respectivo prolongamento (para que se produz, de onde provêm os recursos, grau de dependência, dentre outros), às interferências dos processos que ocorrem "fora" da propriedade e que podem (re)organizar a unidade, bem como à autonomia relativa da propriedade diante de determinada condição. É importante se atentar para a interdependência dos equilíbrios, mas que, para fins de análise, são trabalhados separadamente.

Quadro 1: Equilíbrios e parâmetros de avaliação das unidades camponesas 


\begin{tabular}{|c|l|}
\hline Equilíbrio & \multicolumn{1}{|c|}{ Parâmetros de avaliação } \\
\hline Trabalho-consumo & $\begin{array}{l}\text { Esfera familiar; relação entre as demandas de consumo da família } \\
\text { e a força de trabalho existente dentro dela; produção total e } \\
\text { consumo para suprir todas as necessidades da família. }\end{array}$ \\
\hline Equilíbrio & \multicolumn{1}{|c|}{ Parâmetros de avaliação } \\
\hline Utilidade e penosidade & $\begin{array}{l}\text { Esfera do trabalhador individual; utilidade como esforços extras } \\
\text { necessários para aumentar a produção total (renda total) e } \\
\text { penosidade associada às adversidades (longas jornadas de } \\
\text { trabalho, trabalhar sob condições extremas etc.); natureza } \\
\text { agradável ou extenuante do trabalho rural; relações com o } \\
\text { crescimento da produção (útil ou penoso?). }\end{array}$ \\
\hline Pessoas e natureza & $\begin{array}{l}\text { Conexão entre agricultura e ecologia; coprodução entre o social e } \\
\text { o natural; pessoas e natureza combinadas na prática da } \\
\text { agricultura; interações e transformações contínuas; } \\
\text { maleabilidade dos recursos naturais e desenvolvimento de uma } \\
\text { agricultura endógena; coprodução realçando as habilidades; } \\
\text { reconhecimento dos domínios social e natural. }\end{array}$ \\
\hline Produção e reprodução & $\begin{array}{l}\text { Recursos internos; constante reprodução dos recursos utilizados; } \\
\text { renovação e menor dispêndio de energia. }\end{array}$ \\
\hline Recursos internos e externos & $\begin{array}{l}\text { Recursos externos; escolha entre "fazer" e "comprar"; maior ou } \\
\text { menor dependência do mercado; grau de mercantilização; grau } \\
\text { em que a propriedade está conectada ao mercado; relação entre } \\
\text { recursos (internos ou externos) e penosidade. }\end{array}$ \\
\hline Autonomia e dependência & $\begin{array}{l}\text { Instituições sociais que cercam a produção e distribuição de } \\
\text { riqueza; relações de classe e mecanismos de extração de } \\
\text { excedente; luta por autonomia em um contexto que imponha } \\
\text { dependência e privação. }\end{array}$ \\
\hline $\begin{array}{l}\text { Número de objetos de trabalho (unidades de terras, animais etc.) } \\
\text { e produção por objeto de trabalho; heterogeneidade; estilos de } \\
\text { agricultura. }\end{array}$ \\
\hline
\end{tabular}

Fonte: PLOEG, 2011.

Org.: AUTOR (2017)

Apesar de Chayanov já ter discutido diversos aspectos atinentes a esses equilíbrios, ele restringiu sua análise à unidade camponesa, aos processos de trabalho e às possibilidades de renda da família a partir das próprias necessidades. Considerar-se-ão os aspectos trabalhados por Ploeg como "equilíbrios relacionais" ou aqueles que de alguma forma transferem a análise para além da propriedade, à montante e à jusante.

\subsection{O equilíbrio entre pessoas e natureza}

Falar da agricultura é também abordar a relação e a transformação mútua do homem e da natureza. Sistemas naturais são continuamente renovados 
conforme as práticas agrícolas, e a coprodução (produção conjunta com a natureza) seria uma das bases para a reprodução do campesinato, pois se precisa produzir, mas também viver da terra e sustentá-la, preferencialmente enriquecê-la e aprimorá-la.

Porém, viver em contínuo equilíbrio com a natureza leva o camponês a lidar com uma série de adversidades e incertezas, adaptações que impossibilitam a existência de um comando externo à propriedade, visto que ele deve estar atento e entender tais processos, identificar as possibilidades e dificuldades para, assim, poder produzir de forma suficiente e satisfatória com vistas à própria manutenção.

Nesse entremeio, a coprodução:

[...] exclui padronização, quantificação completa e planejamento apertado. Portanto, requer a unidade camponesa, já que esta associa o desenvolvimento bem equilibrado da coprodução às aspirações emancipatórias do campesinato. Isso se dá na escala micro da unidade camponesa estabelecendo-se solidamente uma conexão direta entre o desdobramento da coprodução e a melhoria da renda de trabalho da família (PLOEG, 2016, p. 61).

Aqui, pode-se observar uma relação direta da coprodução com a melhoria da renda familiar, ou seja, ao equilíbrio entre o trabalho e o consumo. O trabalho se dá no âmbito da natureza, com uma produção voltada à manutenção e ao aperfeiçoamento dos processos naturais para melhor atender às demandas de consumo da família.

Outro ponto relevante a ressaltar são as novas formas que surgem a todo o momento a partir da coprodução. Quando a natureza é remodelada e transformada, modificam-se também os elementos utilizados na produção, em que se criam novas possibilidades em razão da maleabilidade dos processos naturais, o que permite o desenvolvimento de uma agricultura endógena.

Ploeg (2016) discorre ainda sobre o aprimoramento das habilidades dos camponeses a partir da coprodução, além de destacar a importância desse equilíbrio para a agricultura camponesa em razão da reciprocidade entre agricultor e natureza.

Tal relação (...) tem a ver com dar e receber. Tem a ver, como tinha, com donativos que são trocados. O agricultor alimenta e cuida do bezerro, providencia seu abrigo e lhe oferece a oportunidade de crescer até se tornar uma boa vaca leiteira, então ele a alimentará, provavelmente com uma dieta cuidadosamente adaptada às suas necessidades individuais. Em troca, a vaca oferecerá ao agricultor novos, e se tudo der certo, promissores bezerros, e um rico fornecimento de leite que poderá se prolongar durante muitos anos (PLOEG, 2016, p. 62-63). 
Nesse ponto, a reciprocidade é intrinsecamente importante para entender os movimentos de retorno buscados a partir da coprodução. O camponês sempre produz pensando no provimento futuro dos recursos por parte da natureza. Para que o "capital" necessitado por ele seja reaproveitado na própria produção e lhe garanta sobrevivência futura, o camponês se relaciona com a natureza de forma que ela seja a ele generosa.

Diante da constante degradação e transformação da natureza em mercadoria, levada a cabo a partir da lógica empresarial do agronegócio, as relações de reciprocidade consequentemente se definham. Contudo, elas ainda mantêm as unidades camponesas em funcionamento e garantem o abastecimento de alimentos para grande parcela da população mundial.

\begin{abstract}
Elas [as relações de reciprocidade] continuam desempenhando um papel importante, entre as gerações e até entre vizinhos, mediante antigas e também renovadas formas de cooperação. A combinação inteligente de relações mercantis com relações de reciprocidade tornou-se, assim, estratégica. Pode até ser argumentado que o estoque de relações não mercantis (governadas pelo princípio da reciprocidade) é estratégico para a agricultura de hoje e especialmente para sua capacidade de sobrevivência ou de reprodução econômica. [...] Em suma: a maior parte da resiliência da agricultura de hoje reside nessa reserva de relações recíprocas escondidas. A negligência, no entanto, desse recurso estratégico pode ameaçar seriamente a própria continuidade da produção e do abastecimento de alimentos no planeta (PLOEG, 2011, p. 13).
\end{abstract}

A combinação estratégica entre as relações mercantis e as de reciprocidade também é essencial quando se quer analisar tal equilíbrio em unidades camponesas, bem como a permanência menos evidente da segunda em relação à primeira. Elas capacitam o camponês para a fuga da mercantilização de suas terras e recursos, lhe oferecendo autonomia e maiores possibilidades de reprodução.

Nuances do equilíbrio entre pessoas e natureza se desdobram em razão da necessidade de produzir para se reproduzir, ou seja: Como se produz? Em que quantidade se produz? Qual o efeito dessa produção para a manutenção daqueles elementos que serão necessários no futuro? Nesse processo se destacam outros 
equilíbrios primordiais para as unidades camponesas, relativos à sua (re)produção e aos recursos utilizados.

\subsection{Os equilíbrios entre produção e reprodução, recursos internos e externos}

A produção na unidade camponesa não funciona a partir das mesmas lógicas empregadas pelo capital. Todavia, aqui os fatores externos são identificados com maior facilidade, pois as pressões exercidas por eles, bem como a combinação com estímulos internos, podem colocar em risco a reprodução futura dos camponeses.

Diante disso, as preocupações com a energia gasta para exercer determinada atividade, como arar os pastos, ordenhar o gado, cultivar as hortaliças no quintal, produzir para venda nos mercados regionais, modificar o preço do produto no mercado e degradar os ecossistemas circundantes, importam para uma eficácia maior na manutenção desse equilíbrio.

Além das pressões externas, a combinação entre os fatores supracitados e os elementos internos também podem gerar desequilíbrios e ameaçar sua reprodução. Existe a possibilidade de haver melhorias nas condições de produção, mas, para serem reproduzidas em longo prazo, faz-se necessário o acompanhamento das condições elementares à (re)produção.

Um dos exemplos são as políticas de crédito dos bancos agrários, que concediam créditos para atividades produtivas (ainda que não fosse suficiente, na maioria dos casos), porém se abstinham de oferecer qualquer tipo de auxílio às atividades reprodutivas (como a manutenção de cercas) baseados no argumento de que essas atividades são "improdutivas". Ainda que verdadeira essa visão é extremamente limitada e demonstra pouco entendimento quanto à importância de manter o equilíbrio entre produção e reprodução (PLOEG, 2016, p. 69).

Como se pode observar, tanto o Estado como, mais recentemente, as agroindústrias, podem apresentar formas de atenuação de problemas, porém sua reprodução necessita de uma maior manutenção dos recursos disponíveis. As mitigações oferecidas por usinas sucroenergéticas, por exemplo, para atenuar os efeitos socioespaciais das localidades onde atuam, mostram sua incapacidade em 
assegurar reprodução social aos camponeses. Elas oferecem capacidade de produção em curto prazo, mas quase nunca de reprodução dos recursos e dos meios necessários à sua manutenção e autonomia.

Nesse ínterim, os recursos disponíveis na unidade camponesa, sejam eles internos ou externos, são imprescindíveis para sua reprodução. Pensar neste equilíbrio é também fazer uma relação direta com tais recursos e de onde eles provêm.

Paralelamente aos recursos produzidos e reproduzidos na própria terra (os recursos internos), toda unidade, qualquer que seja a localização, também necessita de recursos externos. Seria impossível imaginar as propriedades funcionando sem eles. No entanto, a natureza desses recursos, a sua origem e, principalmente, o modo como são adquiridos e os efeitos do método de aquisição podem ter consequências de enorme alcance (PLOEG, 2016, p. 70).

Mais uma vez, pode-se notar a correlação entre esses equilíbrios e os demais, principalmente aqueles voltados à produção, consumo e reprodução da família. A forma com que os recursos internos e externos serão organizados diz muito sobre a mobilização destinada ao mercado ou à própria unidade.

Assim sendo, a relação entre recursos internos e externos se resume à escolha entre "fazer" e "comprar" (PLOEG, 2016), existindo uma permutação entre os recursos de mercado, os que são produzidos na propriedade e aqueles gerados e regenerados ou comercializados. A conversão dos recursos em produção e a capacidade em reproduzi-los a partir de uma dinâmica renovada é essencial para o equilíbrio atinente à fonte desses recursos.

Surgirá desse equilíbrio uma das principais formas de desmercantilização buscada historicamente pelo campesinato, diminuindo a dependência das unidades no que tange aos recursos externos, em cuja análise busca identificar o grau de dependência da família em relação ao mercado. Como o produto do trabalho é a única fonte de renda do camponês, "o equilíbrio entre esses dois conjuntos de transações resultará em um produto de trabalho aceitável", sempre buscando diminuir ao máximo as despesas referentes aos recursos externos (PLOEG, 2016, p.74). 
Assim como as "reciprocidades escondidas" ainda mantêm de forma satisfatória os modos de vida camponeses, em uma conjuntura de severo abandono dessas práticas, a desmercantilização também garante, em grande medida, a autonomia e o posicionamento do camponês na sociedade capitalista.

\subsection{Os equilíbrios entre autonomia e dependência, escala e intensidade}

O grau de dependência e autonomia da propriedade camponesa é demonstrado por meio de todos os equilíbrios, visto que ele diagnosticará a propriedade e alocará o produtor nessa condição. Como está sendo observado, tal equilíbrio deve considerar todas as instituições que cercam a produção. A extração do excedente e a distribuição de riquezas na sociedade são basilares para entender a condição do camponês em um ambiente que o priva de autonomia e lhe impõe dependência.

Com isso, há os seguintes questionamentos: Quais as instituições (Estado, multinacionais, mercado) levam o camponês a produzir de determinada forma? Como se dá a apropriação da riqueza e do excedente do trabalho por parte dessas instituições? Quais as taxas cobradas, os juros, as tributações e como elas impactam na renda produzida por ele? Qual o grau de expropriação do produto do trabalho e como ela é feita? Essas são algumas perguntas abarcadas nesse equilíbrio para compreender a autonomia e a dependência das unidades.

\footnotetext{
O mesmo acontece quando a análise começa no nível macro, por exemplo, quando perguntamos como uma determinada formação político-econômica afeta o desenvolvimento rural. Então uma compreensão chayanoviana da unidade camponesa precisa ser incluída na análise porque os efeitos de uma formação político-econômica são mediadas por produtores diretos que tentam avaliar os importantes equilíbrios dentro de suas unidades de produção de acordo com os parâmetros vigentes (PLOEG, 2016, p. 76).
}

Nesse sentido, deve-se atentar para os poderes constituídos na sociedade capitalista, com a intenção de entender a formação político-econômica atual e como as instituições delimitam a reprodução do campesinato. 
A identificação do camponês enquanto grupo social específico do modo de produção capitalista o leva a compreender melhor sua situação e luta diante da hegemonia exercida por determinadas instituições. Indagações referentes à sua participação em movimentos sociais, sua autodenominação, enfim, suas percepções acerca da condição que ocupam na sociedade atual também são primordiais para compreender como se dá esse equilíbrio nas unidades.

Já em relação à escala e intensidade de produção, ela está baseada no número de objetos ou instrumentos de trabalho (terra, animais, maquinários etc.) e na produção por objeto (força do trabalho). Como visto na coprodução, uma especificidade da produção agrícola se refere ao fato de os objetos de trabalho fazerem parte da natureza, algo central na relação entre escala e intensidade.

A centralidade da natureza afeta intensamente os processos agrícolas de trabalho e produção. Introduz variabilidade e uma certa imprevisibilidade e requer ciclos permanentes de observação, interpretação, adaptação e avaliação (PLOEG, 2016, p. 113-114).

Juntamente com os instrumentos utilizados (ordenha, pá, foice, tratores, dentre outros), a força do trabalho garante que tal processo seja maleável conforme as condições naturais, podendo assim facilitá-lo e aperfeiçoá-lo - combinações entre força e instrumentos de trabalho asseguram o aparato técnico à coprodução. Cumpre dizer que existem diversas combinações entre esses três fatores, as quais serão medidas por meio da escala de tais objetos e da intensidade do trabalho (reforçado a partir dos instrumentos).

Deve-se compreender que a alocação dos recursos para aumentar a escala ou a intensidade diferencia, em grande medida, a agricultura corporativa daquela exercida por camponeses e pequenos produtores.

A agricultura pode se desenvolver por meio da intensificação contínua, ou ela pode seguir um padrão diferente que diz respeito à ampliação da escala. E, claro, todos os tipos de formas intermediárias são possíveis (PLOEG, 2016, p. 115-116). 
Portanto, a relação quantitativa entre os objetos de trabalho e a força de trabalho para convertê-los em produtos finais úteis será necessária para a manutenção do equilíbrio na unidade camponesa. "A intensificação se refere aos aumentos no rendimento e no processo pelo qual esses aumentos são alcançados", ao passo que a escala diz respeito aos "instrumentos usados, e, mais genericamente, às relações sociais de produção" (PLOEG, 2016, p. 115).

Devemos considerar também os mecanismos de acesso aos elementos que configuram esse equilíbrio. A participação em cooperativas, a organização política e a integração entre camponeses podem trazer maior acesso a informação, elevando sua capacidade de atuação e busca por elementos que fortaleçam a escala e a intensidade de produção (linhas de crédito, acesso à políticas públicas, movimentos sociais dentre outros).

\section{A SUBJETIVIDADE E O PAPEL DA RECIPROCIDADE NAS SOCIEDADES CAMPONESAS}

Diante das características descritas, podemos verificar como os equilíbrios estão direta ou indiretamente conectados entre si, posto que se referem a mesma dinâmica reprodutiva, a exemplo da relação entre pessoas e natureza e as possibilidades de trabalho; entre dependência e autonomia e os recursos internos e externos; entre escala, intensidade da produção e utilidade ou penosidade que se incorpora etc.

Porém, um ponto importante a se destacar concerne às críticas recebidas em razão do caráter "subjetivo" da abordagem chayanoviana, principalmente àquelas vinculadas aos materialistas. Em relação a essa crítica, sabe-se que não se analisam de forma estritamente subjetiva as unidades camponesas, visto que as ações e deliberações da família refletem e devem compreender a realidade material da propriedade (terra disponível, força de trabalho, renda, níveis de preço, acesso ao mercado). 
A avaliação subjetiva não implica capricho e/ou desconexão das realidades materiais da vida. Pelo contrário, trata-se de levar em consideração tais realidades materiais, que muitas vezes podem ser adversas. A questão é que essas realidades materiais não impactam automaticamente - elas impactam por meio da observação ativa do agricultor, de sua interpretação e transformação em um curso de ação correspondente (PLOEG, 2016, p. 53).

Considerado os aspectos materiais estruturantes da unidade camponesa, a análise subjetiva se faz necessária em razão das diferenciações e especificidades que cada unidade comporta em relação à empresa capitalista, como o não pagamento de salários, a acumulação e o lucro.

Além disso, as formas como se dão os equilíbrios na unidade camponesa não são impostas de forma deliberada por agentes econômicos externos, mas sim trabalhadas internamente em cada propriedade. “Os sujeitos conhecedores e capazes coordenam os diversos equilíbrios implícitos dentro da família e da propriedade de maneira experimentada, testada e orientada para seus objetivos" (PLOEG, 2016, p. 5455).

Com isso, em suma

(...) a avaliação subjetiva é intrínseca à agricultura. Talvez o cálculo marginal associado seja tabu dentro de determinadas correntes teóricas ou entre tendências políticas específicas. Mas e daí? Assim temos de ajustar as teorias ou redefinir a posição política. Não é possível pedir que os camponeses evitem fazer cálculos sofisticados e mantenham o olhar aguçado em seus interesses e perspectivas. Essa atitude equivaleria a convidá-los para serem os bobos de sua própria corte (PLOEG, 2016, p. 55).

No tocante à reciprocidade nas sociedades e organizações camponesas, ela pode ser identificada como um princípio que regula sobremaneira sua capacidade de reprodução e a garantia dos equilíbrios em níveis satisfatórios. Em um prefácio esclarecedor sobre o papel da reciprocidade nas sociedades camponesas (SABOURIN, 2011), Ploeg demonstra como tal princípio perpassa as várias relações do camponês com o entorno e a vida cotidiana. Para ele, "a agricultura é, desde tempos antigos, inserida, incorporada em uma ampla gama de relações recíprocas" que não se vinculam apenas às interações entre homem e natureza, mas também à família 
camponesa (pai, mãe, filhos, avós, tios etc.), às gerações (avós trabalharam para os pais, que trabalham para os filhos e assim por diante), aos vizinhos (ajuda mútua, mutirões, trocas), às inter-relações ao nível da comunidade (proteção, reivindicações, serviços) e ao nível de mercado (mercado regional, venda direta em circuitos curtos).

Apesar de estarem fortemente ameaçadas após a modernização agrícola e a liberalização e globalização econômica, as relações de reciprocidade, de acordo com o autor, ainda são responsáveis por garantir a manutenção das famílias camponesas no mundo.

Elas continuam desempenhando um papel importante dentro da família, entre as gerações e até entre vizinhos, mediante antigas e também renovadas formas de cooperação. [...] Em suma: a maior parte da resiliência da agricultura de hoje reside nessa reserva de relações recíprocas escondidas. A negligência, no entanto, desse recurso estratégico pode ameaçar seriamente a própria continuidade da produção e do abastecimento de alimentos no planeta (PLOEG, 2011, p. 12).

Como postulado por Ianni (2016), essas e outras premissas vinculadas ao campesinato conservam características que poderiam reorientar a sociedade como um todo. A organização baseada na reciprocidade revê questões nas quais a própria sociedade capitalista se desvincula, visto o caráter lucrativo e de troca estabelecido com a terra.

\begin{abstract}
Em essência, o seu caráter radical está no obstáculo que representa à expansão do capitalismo, na afirmação do valor de uso sobre o valor de troca, sobre a mercadoria, enquanto tal, sobre o trabalho alienado, na resistência da transformação da terra em monopólio, na afirmação de um modo de vida e trabalho que tem evidentemente uma conotação comunitária. Uma organização em que a participação do todo é de outro tipo e em que a distribuição do produto material e espiritual é de outro tipo.

Nesse sentido, há na comunidade camponesa ou nas formas camponesas de viver e trabalhar uma sugestão ou uma metáfora do que poderia ser o modo futuro de organizar a sociedade (IANNI, 2016, p. 65).
\end{abstract}

Porquanto, o território camponês segue uma lógica que se comporta como verdadeiro "contra espaço" (HAESBAERT, 2002) no modo de produção capitalista. A interdependência entre os diversos fatores que compõem o território, seja em relação à representatividade cultural (símbolos, identidades) ou à materialidade (terra, trabalho, consumo), é sempre considerada ao se buscar um equilíbrio ótimo da 
unidade. Identificar os variados fatores e as adaptações diante da realidade vivenciada atualmente se faz necessário para compreender a produção do território camponês, suas aspirações e a importância de ser mantido.

\section{CONSIDERAÇÕES FINAIS}

Diante do exposto e da caracterização dos equilíbrios, salienta-se que os estudos sobre campesinato a partir de tal metodologia podem oferecer informações importantes em relação às transformações e à reprodução sociocultural desses grupos. Em intervalos de tempo maiores, com o monitoramento de tais elementos em circunstâncias específicas (visto que alguns equilíbrios necessitam de uma análise mais aprofundada, com mais evidências do funcionamento de cada unidade e da relação com seu exterior), é possível evidenciar precisamente aspectos imprescindíveis para o reconhecimento da realidade e dos problemas atinentes às organizações e sociedades camponesas nos dias atuais.

Informações coletadas possibilitam um avanço à teoria chayanoviana, bem como a compreensão das diferentes formas de disputa e das transformações relativas ao campesinato e ao seu embate com o território do capital no campo, suas características e organização na atual conjuntura do desenvolvimento rural brasileiro, nas diversas regiões do país.

A análise dos equilíbrios ora proposta tem foco na produção de dados específicos de cada unidade camponesa e pretende identificar as possíveis transformações em tais equilíbrios, bem como as estratégias frente à (re)organização territorial provocada pelo avanço do agronegócio. Apesar de discriminados, os equilíbrios são interdependentes e se relacionam à organização da unidade como um todo. A divisão é, portanto, um recurso analítico que necessita de ponderações.

Conforme os equilíbrios propostos, é preciso se atentar para outros que, por vezes, podem ser identificados ou mesmo trabalhados de forma indireta naqueles já destacados. Nesse sentido, as constatações e os elementos não se findam nos limites 
aqui discutidos, abrindo espaço para uma gama maior de equilíbrios que possam ser utilizados na compreensão de realidades específicas a que estão sujeitos os camponeses, além das transformações a partir do embate com diferentes territórios e modelos produtivos.

Para a Geografia, o presente texto é uma proposta metodológica a ser empregada nos estudos rurais para reconhecer os territórios camponeses, suas formas estrutural e conjuntural, as transformações empreendidas pelo agronegócio e o modelo capitalista de produção aos territórios alternativos a ele, com destaque às populações tradicionais e à pequena produção.

Destarte, os equilíbrios camponeses estão longe de se resumirem aos aspectos discutidos neste artigo. Isso pode ser visto como um avanço ainda maior para a presente metodologia, a qual se encontrará em constante construção e aperfeiçoamento, a depender de cada realidade, disputa e território presente na análise, além dos diferentes períodos históricos e dos novos modelos aos quais está sujeito o rural contemporâneo.

\section{REFERÊNCIAS}

CHAYANOV, A. V. La organización de la unidad económica campesina. Buenos Aires: Ediciones Nueva Visión, 1974.

CHAYANOV, A. The theory of peasant Co-operatives. Columbus: Ohia State University Press, 1991 [1927].

HAESBAERT, Rogério.Territórios alternativos. São Paulo: Contexto, 2002.

IANNI, Octavio. A utopia camponesa. In: STEDILE, João Pedro (Org.) A questão agrária no Brasil 9: Interpretações sobre o camponês e o campesinato. São Paulo: Expressão Popular, 2016. Cap. 3. p. 55-70.

KAUTSKY, Karl. A questão agrária. Tradução de Otto Erich W. Mass. São Paulo: Nova Cultura, 1986. (Os economistas).

LENIN, V. I. O desenvolvimento do capitalismo na Rússia. Tradução de José Paulo Netto. São Paulo: Nova Cultural, 1980. v. 1. (Os economistas).

MENDES, Heitor Nascimento. Expressões territoriais camponesas da comunidade Boa Esperança/Frutal (MG): os equilíbrios da unidade camponesa frente ao avanço do agronegócio 
canavieiro. 2018. 153 f. Dissertação (Mestrado) - Curso de Geografia, Instituto de Geografia, Universidade Federal de Uberlândia, Uberlândia, 2018. Cap. 5. Disponível em: https://repositorio.ufu.br/handle/123456789/20805. Acesso em: 31 jul. 2018.

PAULINO, Eliane Tomiasi; ALMEIDA, Rosemeire Aparecida de. Terra e Território: A questão camponesa no capitalismo. São Paulo: Expressão Popular, 2010.

PLOEG, Jan Douwe van Der. Camponeses e a arte da agricultura: Um manifesto chayanoviano. São Paulo; Porto Alegre: UNESP; UFRGS, 2016.

PLOEG, Prefácio. In: SABOURIN, Eric. Sociedades e organizações camponesas: Uma leitura através da reciprocidade. Porto Alegre: UFRGS, 2011, p. 11-14.

PLOEG, Prefácio.. O modo de produção camponês revisitado. In: SCHNEIDER, Sérgio (Org.). A diversidade da agricultura familiar. Porto Alegre: UFRGS, 2006. Cap. 1. p. 13-54.

RAFFESTIN, Claude. A produção das estruturas territoriais e sua representação. In: SAQUET, Marcos Aurélio; SPOSITO, Eliseu Savério (Org.). Territórios e territorialidades: teorias, processos e conflitos. São Paulo: Expressão Popular, 2009. Cap. 1. p. 17-35.

SABOURIN, Eric. Sociedades e organizações camponesas: Uma leitura através da reciprocidade. Porto Alegre: UFRGS, 2011.

TEDESCO, João C. Terra, trabalho e família: racionalidade produtiva e ethos camponês. Passo Fundo: ED 